\section{AUTHOR}

TI TLE

INST ITUTION REPORT NO PUB DATE

NOTE

PUB TYPE

EDRS PRICE

DESCRIPTORS

IDENT I F IERS
Zwick, Rebecrz; Etcikan, Kadriye

Analysis of Differential Item Functioning in the NAEP History Assessment.

Educational Testing Service, Princeton, N.J. ETS-RR-88-66

Nov 88

$32 \mathrm{p}$.

Reports - Evaluative/Feasibility (142)

MF01/PCO2 Plus Postage.

Blacks; *Ethnic Groups; Grade 11; High Schools; "High School Students; Hispanic Americans; *History; *Item Bias; Nationai Surveys; Sex Differences; *Test It ems Item Bias Detection; *Mantel Haenszel Procedure; *National Ase zssment of Educational Progress

ABSTRACT

The Mantel-Haenszel approach for investigating differential item functioning (DIF) was applied to U.S. history items that were administered as part of the National Assessment of Educational Progress (NAEP). DIF analyses were based on the responses of 7,743 students in grade 11 . On some items, Blacks, Hispanics, and females performed more poorly than other students, conditional on number-right score. It was hypothesized that this resulted in part from the fact that ethnic and gender groups differed in their exposure to the material included in the assessment. Supplementary Mantel-Haenszel analyses were undertaken in which the number of historical periods studied, as well as score, was used as a conditioning variable. Contrary to expectation, the additional conditioning did not lead to a reduction in the number of DIF items. Both methodological and substantive explanations for this unexpected result were explored. (Contains 12 tables and 4 references.) (Author/SLD)

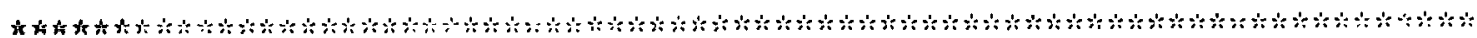
$* \quad$ Reproductions supplied by EDRS are the best that can be made * $\because$ from the original document. $\quad *$

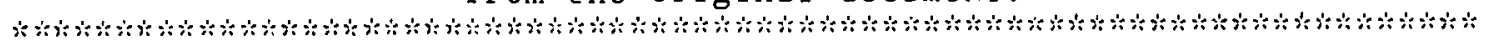


U S DEPAMTMENT OF EOUCATIOH Orice of Educatronal Reseaich and imporement EDUCATIONAL RE SOURCES INFORMATION

Vhis oocument has meen reproduced as cecored tiom the ison or organization Originaling "l

Minor chanoes have been made to inprore reproduction quality

- Poinis of vieu or opimions stated in this docu menl do mol necessarilit tepresent ollicia OEAI position at policy

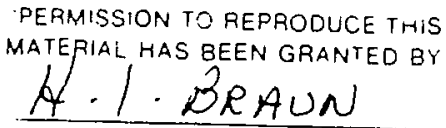

MATERIAL HAS

A. T. DRAUN

TO THE EDUCATIONAL RESOURCES INFORMATION CENTER IERICI

\title{
ANALYSIS OF DIFFERENTIAL ITEM FUNCTIONING IN THE NAEP HISTORY ASSESSMENT
}

\author{
Rebecca Zwick \\ Kadriye Ercikan
}

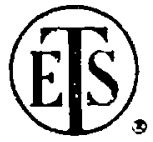

Educational Testlng Service

Princeton, New Jersey

November 1988

\section{BEST COPY AVAILABLE}


Analysis of Differential Item Functioning in the NAEP History Assessment Rebecca Zwick

Educational Testing Service

Kadriye Ercikan

Stanford University

November 8,1988 


\section{Acknowledgments}

The authors thank Paul Holland for consultation and Jennifer Nelson and Laurie Barnett for statistical programming assistance. A portion of this work was conducted while the second author was a predoctoral fellow at ETS. 
Abstract

The Mantel-Haenszel approach for investigating differential item functioning (DIF) was applied to U.S. history items that were administered as part of the National Assessment of Educational Progress (NAEP). On some items, Blacks, Hispanics, and females performed more poorly than other students, conditional on number-right score. It was hypothesized that this resulted in :art from the fact that ethnic and gender groups differed in their exposure to the material included in the assessment. Supplementary Mantel-Haenszel analyses were undertaken in which the number of historical periods studied, as well as score, was used as a conditioning variable. Contrary to expectation, the additional conditioning did not lead to a reduction in the number of DIF items. Both methodological and substantive explanations for this unexpected result were explored. 
The National Assessment of Educational Progress is a survey of the academic achievements of American students that began in 1969. The MantelHaenszel (1959) approach to differential item functioning (DIF) analysis developer by Holland and Thayer (1988) was applied to U.S. history items that were administered in 1986 as part of a project supported by NAEP and the National Endowmert for the Humanities (see Applebee, Langer, \& Mullis, 1987). On about 30 percent of the items, there was sore evidence that either Blacks, Hispanics, or females performed more poorly than other students, conditional on number-right score.

It was hypothesized that this could have resulted in part from the fact that ethnic and gender groups differed in their exposure to the material included in the history assessment. In this study, the results of a standard Mantel-Haenszel DIF analysis are compared to results obtained from: supplementary analyses in which history course background, as well as score, is used as a conditioning variable. The purpose of this more refined matching procedure is to achieve a situation ir. which item performance is compared for groups of students who are of similar overall proficiency and have been exposed to similar curricula. If the original findings were indeed a reflection of differences in curriculum exposure, the new analyses should produce fewer DIF items.

\section{The U.S. History Assessment}

History items were included in four of the 92 booklets administered to a national sample of students who were 17 years old or in grade 11 in the 1986 NAEP assessment. Each of the four booklets contained one of four history blocks ( $\mathrm{Hl}, \mathrm{H} 2, \mathrm{H} 3$, or $\mathrm{H} 4)$, as well as a block of literature items and a block of reading items. The objectives for the history assessinent, as well as 
the items themselves, were developed through consultation with a committee of U.S. history specialists. Potential items were then reviewed by more than fifty educators from around the country. Each U.S. history block consisted of 34 to 36 cognitive itens and a common set of history background items, which included questions abrut previous courses in history. The four history blocks were constructed to be parallel in content and yielded similar item analysis results, although block $\mathrm{Hl}$ was scr. what easier than the remaining three blocks (see Table 1). The students who took each of the four blocks were random samples from the same population. As in all NAEP assessments, no results were reported at the individual student level.

For reporting the history results, NAEP used item response theory methods to derive a scale, based on the responses of the 7812 students who were in grade 11. DIF analyses were based on the responses of 7743 eleventh graders; students who failed to answer any items or who received defective test booklets were excluded.

In interpreting the results described here, it is necessary to consider that NAEP collects data using a stratified multistage cluster sampling scheme in which students have differential probabilities of selection. As in most surveys, each respondent is assigned a sampling weight. Based on preliminary investigation, it appears that the NAEP sampling weights have little impact on the Mantel-Haenszel delta difference (MH D-DIF) statistic (Equation 7). However, because of cluster effects, the distributions of MH D-DIF and the Mantel-Haenszel chi-square (MH CHISQ) statistic (Equation 3) will differ from their distributions under simple random sampling. In the analyses described here, no adjustment was made for the complex sampling scheme. Therefore, the significance probabilities (p-values) discussed in the following sections can 
Table 1

NAEP History Assessment:

Descriptive Statistics

\begin{tabular}{|c|c|c|c|c|c|c|}
\hline Block & $\begin{array}{c}\text { Numbers of } \\
\text { Items }\end{array}$ & $\begin{array}{c}\text { KR }-20 \\
\text { Reliability }\end{array}$ & $\begin{array}{c}\text { Average } \\
\text { Tetrachoric }\end{array}$ & Mean & S.D. & Mean $p$ \\
\hline $\mathrm{HI}$ & 36 & .84 & .39 & 20.8 & 6.3 & .58 \\
\hline $\mathrm{H} 2$ & 36 & .83 & .35 & 19.2 & 6.4 & 53 \\
\hline H3 & 35 & .82 & .40 & 16.9 & 6.1 & 48 \\
\hline $\mathrm{H} 4$ & 34 & .87 & .48 & 19.2 & 6.9 & 57 \\
\hline
\end{tabular}


be assumed to depart to some degree from the actual significance probabilities. The classification of items into A, B, and C categories could also be affected. The focus of the present study, however, is the comparison of two competing analysis methods: 1) conditioning on score only and 2) conditioning on both score and history course background.

\section{Analysis 1: Conditioning on Score Only}

Within each of the four history blocks, DIF analyses were conducted to compare the performance of males and females, Whites and Blacks, and whites and Hispanics, conditional on number-right score. The sample sizes for each group are given in Table 2 .

The standard Mantel-Haenszel (1959) approach to DIF anaiysis, cieveloped by Holland and Thayer (1988), involves the creation of $\mathrm{K}$ two-by-two tables, where $\mathrm{K}$ is the number of score categories. Because there were few examinees at the lower end of the distribution, scores $0-6$ and scores $7-9$ were collapsed. This collapsing scheme was selected over other possible schemes because it minimized the number of unmatched focal group members. For the $k^{\text {th }}$ score level, the data can be displayed as in Table 3. Here, F denotes the focal group (Blacks, Hispanics, and females, respectively, in the analyses considered here) and $R$ denotes the refererice group. The numbers of examinees in the $R$ and $F$ groups are denoted by $n_{R k}$ and $n_{F k}$, respectively; $m_{1 k}$ represents the rumber of examinees who answered the item correctly and $m_{0 k}$ is the number who answered incorrectly. $A_{k}$ and $C_{k}$ denote the numbers of examinees in the $R$ and $F$ groups, respectively, who answered correctly; $B_{k}$ and $D_{k}$ aire the numbers of examinees in the $R$ and $F$ groups who answered incorrectly. $T_{k}$ is the total number of examinees. (For both Analysis 1 and Analysis 2, examinees who did not reach an item were excluded from the DIF analysis for that item. This eliminates problems in interpretation that can 
Table 2

Sample sizes for DIF Analyses

\begin{tabular}{lrrrrc}
\hline & Male & Female & White & Black & Hispanic \\
H1 & 964 & 989 & 1375 & 321 & 198 \\
H2 & 945 & 984 & 1365 & 330 & 168 \\
H3 & 935 & 975 & 1346 & 306 & 201 \\
H4 & 1018 & 933 & 1410 & 308 & 185 \\
\hline
\end{tabular}

Note. Six examinees were excluded from Analysis 2 because they were missing information on historical periods studied. Students who failed to reach an item were excluded from the DIF analysis for that item. 
Table 3

Data for the $k^{\text {th }}$ Matched Set of Reference and Focal Group Members Score on Studied Item

\begin{tabular}{|c|c|c|c|}
\hline \multicolumn{4}{|c|}{ Score on Studied } \\
\hline Group & 1 & 0 & Total \\
\hline $\mathrm{R}$ & $A_{k}$ & $\mathrm{~B}_{k}$ & $\mathrm{n}_{\mathrm{Rk}}$ \\
\hline F & $c_{k}$ & $D_{k}$ & $\mathrm{n}_{\mathrm{Fk}}$ \\
\hline Total & $\mathrm{m}_{1 \mathrm{k}}$ & $\mathrm{m}_{\mathrm{Ok}}$ & $T_{k}$ \\
\hline
\end{tabular}


result when the focal groups and reference groups have different rates of completing the item block.)

As described in Holland and Thayer (1988), it is assumed that, within each stratum, data for the $R$ and $F$ groups have been acquired by obtaining (simple) random samples of fixed sizes ( $n_{\mathrm{Rk}}$ and $\mathrm{n}_{\mathrm{Fk}}$ ) from pools of reference and focal group members. $A_{k}$ and $C_{k}$ are then independent binomial random variables with parameters $\left(n_{R k}, P_{R k}\right)$ and $\left(n_{F k}, P_{F k}\right)$, respectively. In the present context, $\mathrm{p}_{\mathrm{Rk}}$ represents the probability of answering the item correctly for members of the reference group in the $k^{\text {th }}$ stratum; $\mathrm{p}_{F k}$ is the corresponding probability for the focal group. We wish to test the hypothesis

$$
\begin{aligned}
& \mathrm{H}_{0}: \frac{\mathrm{p}_{\mathrm{Rk}}}{{ }_{\mathrm{q}}} / \frac{\mathrm{p}_{F k}}{{ }_{\mathrm{q} k}}=1, k=1,2, \ldots \mathrm{k} \\
& \text { versus } \\
& \mathrm{H}_{1}: \frac{\mathrm{p}_{\mathrm{Rk}}}{{ }_{\mathrm{q}}} / \frac{{ }_{\mathrm{Rk}}}{{ }_{\mathrm{q}} \mathrm{Fk}}=\omega, \omega \neq 1
\end{aligned}
$$

The parameter $\omega$ represents the common odds ratio for the $k 2 \times 2$ tables. The uniformly most powerful unbiased test of $\mathrm{H}_{0}$ versus $\mathrm{H}_{1}$ is provided by the Mantel-Haenszel chi-square statistic:

$$
\text { MH CHISQ }=\frac{\left(\left|\sum A_{k}-\sum E\left(A_{k}\right)\right|-1 / 2\right)^{2}}{\sum_{k} \operatorname{Var}\left(A_{k}\right)}
$$

where

$$
E\left(A_{k}\right)=n_{R k} m_{1 k} / T_{k}
$$


and

$$
\operatorname{Var}\left(A_{k}\right)=\frac{\mathrm{n}_{\mathrm{Rk}} \mathrm{n}_{\mathrm{F}}^{\mathrm{m}} 1 \mathrm{k}^{\mathrm{m}} \mathrm{Ok}}{\mathrm{T}_{k}^{2}\left(\mathrm{~T}_{k}-1\right)} .
$$

The statistic in [3] has a chi-square distribution with one degree of freedom when the stated assumptions are met and $\mathrm{H}_{0}$ is true. Mantel and Haenszel provided the following estimator of $\omega$ :

$$
\hat{\omega}_{M H}=\frac{\sum A_{k} D_{k} / T_{k}}{\sum B_{k} C_{k} / T_{k}} .
$$

At ETS, the statistic typically used as an index of differential item performance is

$$
M H D-D I F=-2.35 \ln (\hat{\omega})
$$

(see Holland and Thayer, 1988). Using the preceding formulation will result in negative values of $\mathrm{MH}$ D-DIF for items that favor the reference group and positive value for items that favor the focal group.

The following rules have betn developed for use by ETS testing programs in interpreting the results of DIF analyses:

"A" items are those for which MH D-DIF is not significantly different from $0(\alpha=.05)$ or has an absolute value less than 1 . These itelits are considered to be free of DIF.

"B" items are those for which MH D-DIF is significartly different from 0 $(\alpha=.05)$ and has cither (a) an absolute value at least 1 but less than 1.5 or (b) an absolute value at least 1 but not significaltly greater than $1(\alpha=$ 05). These items may be used, but if there is a choice among otherwise equivalent items, it is considered desirable to select for inclusion in a 
rest those with the smallest absolute value of MH D-DIF.

"C" items are those for which the absolute value of MH D-DIF is at least 1.5 and is significantly greater than $1(\alpha=.05)$. These items are to be -elected only if essential to meet test specifications.

For purposes of this study, the NAEP U.S. history items were classified into A, B, and C categories. Results were tabulated separately for items that favored the reference group (conditional on score) and those that favored the focal group. The right margins of Tables 4, 5, and 6 show the numbers of DIF items for Analysis 1 according to this classification system. For example, the right margia of Table 4 shows that in Analysis 1 , the malefemale comparison yiulded $51+12+4=67$ items for which MH D-DIF was negative, indicating that males performed better on the item, conditional on score. Of these items, 51 were A items and thus not of concern, 12 were B items, and 4 were $C$ items. On 74 items, the conditional performance of females was better. These items included $60 \mathrm{~A}, 13 \mathrm{~B}$, and one $\mathrm{C}$ item.

Tables 7,8 , and 9 snow the results obtained if only the statistical significance of the chi-square values is corividered in classifying items. For example, of the 67 items with negative values of MH D-DIF in Analysis 1 , Table 7 shows that 25 wer 2 statistically significant at $\alpha=.01$. These tables, as well as the Analysis 2 results are discussed in later sections.

Although the results of Analysis 1 were not always interpretable with respect to item content and type, certain meaningful patterns were evident. particularly with regard to the $\mathrm{C}$ items.

First, consider the male-fernale analyses. All four $C$ items that were easier for males, conditional on score, pertained to World war I or World $w$ ar II; two of these asked for dates. Among the 12 B items that were 
Table 4

Results of Male-Female Anclyses:

Numbers of $A, B$, and $C$ Items

\begin{tabular}{|c|c|c|c|c|c|c|c|c|}
\hline \multirow{3}{*}{ Analys is 1} & & \multicolumn{6}{|c|}{ Analys:s 2} & \multirow[b]{3}{*}{ Total } \\
\hline & & \multicolumn{3}{|c|}{ Male + } & \multicolumn{3}{|c|}{ Female +} & \\
\hline & & A & B & $\mathrm{C}$ & A. & $\mathrm{B}$ & $\mathrm{C}$ & \\
\hline \multirow[t]{3}{*}{ Male + } & A & 46 & 2 & 0 & 3 & 0 & 0 & 51 \\
\hline & B & 0 & 12 & 0 & 0 & 0 & 0 & 12 \\
\hline & $\mathrm{C}$ & 0 & 1 & 3 & 0 & 0 & 0 & 4 \\
\hline \multirow[t]{3}{*}{ Female + } & $A_{2}$ & 1 & 0 & 0 & 58 & 1 & 0 & 60 \\
\hline & $B$ & 0 & 0 & 0 & 1 & 12 & 0 & 13 \\
\hline & $\mathrm{C}$ & 0 & 0 & 0 & 0 & 0 & 1 & 1 \\
\hline
\end{tabular}

Total

47

153

$62 \quad 13$

141

Note. The labels "Male +" and "Female +" indicate which group showed superior conditional performance on the corresponding items. 
Table 5

Results of White-Black Analyses: Numbers of $A, B$, and $C$ Items

\begin{tabular}{|c|c|c|c|c|c|c|c|c|}
\hline \multirow{3}{*}{ Analysis 1} & & \multicolumn{6}{|c|}{ Analysis 2} & \multirow[b]{3}{*}{ Tota] } \\
\hline & & \multicolumn{3}{|c|}{ White + } & \multicolumn{3}{|c|}{ Black + } & \\
\hline & & $\mathrm{A}$ & B & $\mathrm{C}$ & $\mathrm{A}$ & $B$ & $\mathrm{C}$ & \\
\hline \multirow{3}{*}{ White + } & $A$ & 50 & 0 & 0 & 0 & 0 & 0 & 50 \\
\hline & B & 0 & 14 & 1 & 0 & 0 & 0 & 15 \\
\hline & C & 0 & 0 & 0 & 0 & 0 & 0 & 0 \\
\hline \multirow{3}{*}{ Black + } & $A$ & 3 & 0 & 0 & 61 & 1 & 0 & 65 \\
\hline & B & 0 & 0 & 0 & 2 & 6 & 0 & 8 \\
\hline & C & 0 & 0 & 0 & 0 & 0 & 3 & 3 \\
\hline
\end{tabular}

$\begin{array}{llllllll}\text { Total } & 54 & 14 & 1 & 63 & 7 & 3 & 141\end{array}$ Note. The labels "White + " and "Black + " indjcate which group showed superior conditional performance on the corresponding items. 
Table 6

Results of White-Hispanic Analyses: Numbers of $A, B$, and $C$ Items

\begin{tabular}{|c|c|c|c|c|c|c|c|c|}
\hline \multirow[b]{3}{*}{ Analys is 1} & & \multicolumn{6}{|c|}{ Analys is 2} & \multirow[b]{3}{*}{ Total } \\
\hline & & \multicolumn{3}{|c|}{ White + } & \multicolumn{3}{|c|}{ Hispanic + } & \\
\hline & & $\mathrm{A}$ & $B$ & $\mathrm{C}$ & $\mathrm{A}$ & $B$ & $\mathrm{C}$ & \\
\hline & $A$ & 46 & 4 & 0 & 6 & 0 & $\overline{0}$ & 56 \\
\hline White + & B & 0 & 14 & 1 & 0 & 0 & 0 & 15 \\
\hline & $\mathrm{C}$ & 0 & 0 & 0 & 0 & 0 & 0 & 0 \\
\hline & A & 1 & 0 & 0 & 58 & 0 & 0 & 59 \\
\hline Hispanic + & B & 0 & 0 & 0 & 7 & 3 & 0 & 10 \\
\hline & $\mathrm{C}$ & 0 & 0 & 0 & 0 & 0 & 1 & 1 \\
\hline
\end{tabular}

Total 47 18 71 3 141 Note. The labels "White + " and "Hispanic +" indicate which group showed superior conditional performance on the corresponding items. 
Table 7

Results of Male-Female Analyses:

Numbers of Items With Chi-Square

Not Significant/Significant at $\alpha=0.01$

Analys is 2

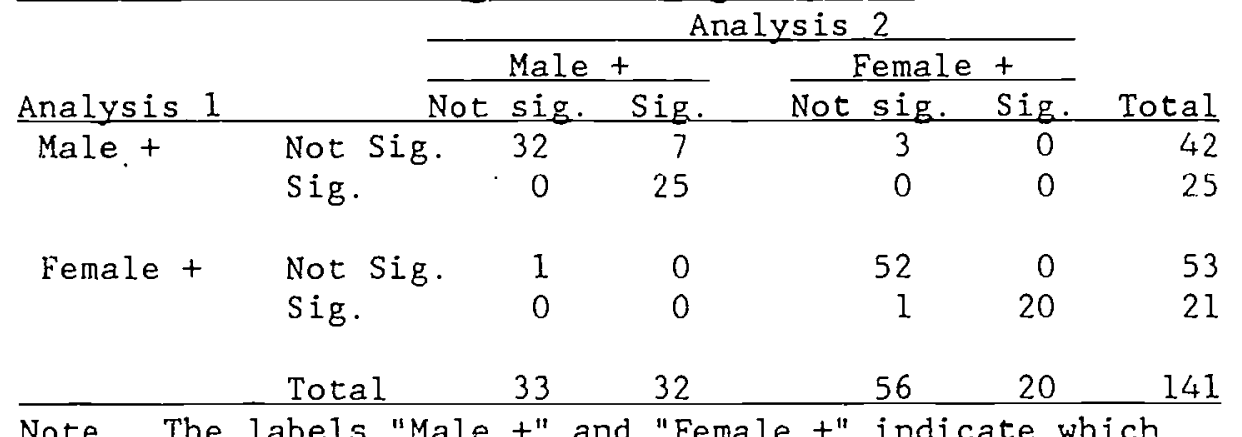

Note. The labels "Male + " and "Female + " indicate which group showed superior conditional performance on the corresponding items. 
Table 8

Results of White-Black Analyses:

Numbers of Items With Chi-Square

Not Significant/Significant at $\alpha=0.01$

\begin{tabular}{|c|c|c|c|c|c|c|}
\hline \multirow{3}{*}{ Analysis 1} & & \multicolumn{4}{|c|}{ Analysis 2} & \multirow[b]{3}{*}{ Total } \\
\hline & & \multicolumn{2}{|c|}{ White + } & \multicolumn{2}{|c|}{ Black + } & \\
\hline & & Not si & Sig. & Not sig & Sig & \\
\hline & Not Sig & 33 & 13 & 0 & 0 & 46 \\
\hline White + & Sig. & 0 & 19 & 0 & 0 & 19 \\
\hline & Not Sig & 3 & 0 & 59 & 0 & 62 \\
\hline Black + & Sig. & 0 & 0 & 5 & 9 & 1.4 \\
\hline & Total & 36 & 32 & 64 & 9 & 141 \\
\hline
\end{tabular}

Note. The labels "White +" and "Black +" indicate which group showed superior conditional performance on the correspunding items. 
Tabie:

Results of White - Hispanic Analyses:

Numbers of Items with Chi-Square

Not Significant/Significant at $\alpha=0.01$

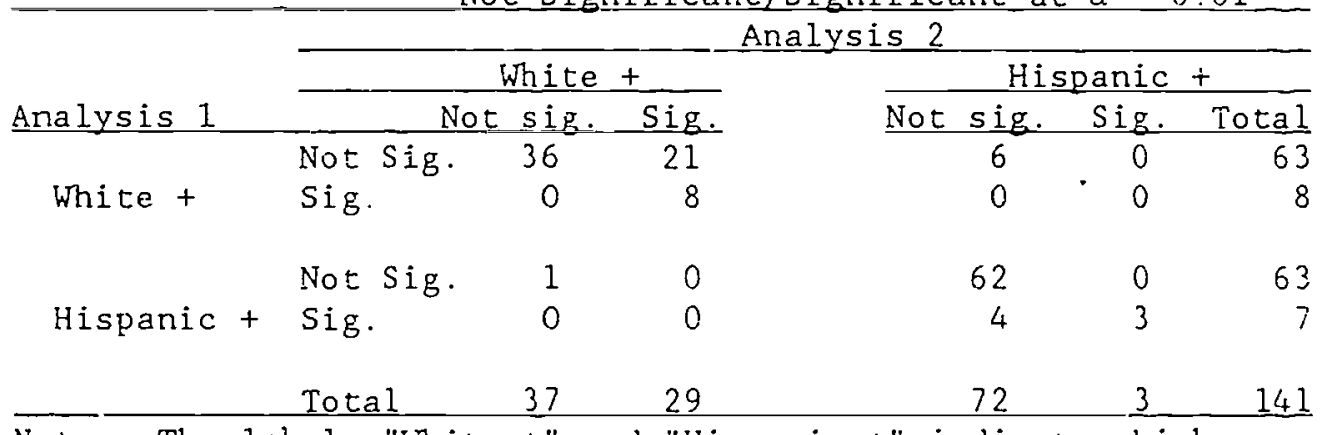

Note. The labels "White + " and "Hispanic + " indicate which group showed superior conditional performance on the corresponding items. 
conditionally easier for males, 3 were also about war and 7 asked for dates.

Only a single $C$ item that was conditionally easier for females was

found: in item asking who was the inventor of the telephone! of the $13 \mathrm{~B}$ items that were conditionally easier for females, 4 pertained to slavery or segregation and 2 were about vomen's voting rights.

In the White-Black analysis, there were no $C$ items that were conditionally easier for whites. The $15 \mathrm{~B}$ i.tems that were conditionally easier for whites included 7 items involving map reading and 4 items on worid War II. The $3 \mathrm{C}$ items on which Blacks performed better than whites, conditional on score, were about Martin Luther King, Harriet Tubman, and the Underground Railroad. The 8 B items that were conditionally easier for Blacks included 2 on slavery, 3 on the civil rights movement, and one on women's rights.

In the White-Hispanic analysis, there were again no $C$ items that were conditionally easier for whites. The single $\mathrm{C}$ item on which the performance of Hispanics exceeded that of whites, conditional on score, was an item about Latin American and Asian immigration to the United States in the $1970^{\prime} \mathrm{s}$ and 1980's. The 10 B items that were conditionally easier for Hispanics included another item about immigration, an item requiring identification of the part of the U.S. that fought for independence from Mexico, an item about Lincoln, and an item about the Emancipation Proclamation. Oddly enough, however, the $15 \mathrm{~B}^{\prime}$ items that were conditionally easier for whites than for Hispanics included 3 items on slavery or segregation and one item on the increase in women in the work force during World war II.

Two of the findings mentioned above involve item type rather than item content: the superior performance of thites over Blacks on map items and 
males over females on date items. To explore these results further, consider the results displayed in Tables 10 and 11 . This type of analysis allows us to see that about 58 percent of map items were conditionally easier for Whites than for Blacks, compared to only about six percent of non-map items. About 30 percent of date items were conditionally easier for males, compared to about six percent of non-date items. In some cases, classification of items inco categories (e.g., war vs. non-war items) is not clearcut. In general, however, constructing tables of this kind is helpful in determining the relevance of item type or content to DIF status.

Analyses of the distractors chosen by each demographic group were conducted to explore the reasons for DIF in greater detail. In general, however, theru as no evidence that the group with lower conditional performance was being lured by any particular distractor. An exception is the item on Martin Luther King. When asked what event marked King's achievement of naticnal prominence, 25 percent of Whites, compared to only 8 percent of Blacks, gave the incorrect response, "Brown vs. Board of Education case in $1954 . "$

Analysis 2: Conditioning on Both Score and Number of Historical Periods studied

As part of the history assessment, students were asked to indicate whether they had studied, since grade 9, the following periods of American history, which were included in the assessment: Exploration, Revolutionary War - War of 1812, Territorial Expansion - Civil War, Reconstruction - World War I, World War I - World War II, and World War II - Present. Students were classified according to the number of historical periods they claimed to have 
Table 10

White-Black Analysis of Map Items

\begin{tabular}{lrrr}
\hline & DIF & Not DIF & Total \\
\hline Map & 7 & 5 & 12 \\
Not Map & 8 & 121 & 129 \\
Total & 15 & 126 & 141 \\
\hline
\end{tabular}

Note. $B$ items on which whites

performed better than Blacks,

conditional on score 
Table 11

Male-Female Analysis of Date Items

DIF Not DIF Total

Date $\quad 9 \quad 21 \quad 30$

$\begin{array}{llll}\text { Not Date } & 7 & 104 & 111\end{array}$

$\begin{array}{llll}\text { Total } & 16 & 125 & 141\end{array}$

Note. $B$ and $C$ items on which males performed better than females, conditional on score 
studied. The number of historical periods studied (hereafter called Periods Studied) had a strong relation to overall performance $n:$ the MAEP history assessment. The first two lines of Table 12 show the estimated percent of eleventh graders in the nation associated with each level of Periods Studied, along with the mean history scale value for each level. Standard errors of means and percents are given in parentheses. The remainder of the table gives the corresponding information for males, females, Whites, Blacks, and Hispanics.

The history scale values have a mean of 285 and a standard deviation of 40 for the eleventh grade sample. It is clear that Periods studied is strongly associated with the history scale values. For the total sample, the difference in history means between those who had studied $0-2$ periods and those who had studied 6 was more than three-quarters of a standard deviation. Also, the distribution for Whites differed from those of Blacks and Hispanics, particularly in the tails. For instance, whereas 32 percent of Whites had studied all 6 periods, only 24 percent of Blacks and 22 , perce:lt of Hispanics had done so. The distributions for males and females were quite similar, although males were somewhat more likely to have studied all 6 periods. The rationale for Analysis 2 was that, by conditioning on Periods Studied as well as score, examinees would be more closely matched. It was expected that this more refined conditioning would produce a smaller number of iteins showing DIF in favor of the reference groups.

In conducting Analysis 2, the collapsing scheme for score was the same as in Analysis 1. Periods Studied was grouped into five categories: $0 \cdot 2,3$, 4, 5, and 6. For each history block, the number of stratification levels for. Analysis 2 was, therefore, five times the number of levels for Analysis 1. 
Table 12

Distribution of Number of Historical Periods Studied and History Scale Means

\begin{tabular}{|c|c|c|c|c|c|c|c|c|}
\hline \multirow[b]{3}{*}{ Total } & \multirow{3}{*}{$\frac{\text { Sample Size }}{7764}$} & \multicolumn{7}{|c|}{ Number of Historical Periods Studied } \\
\hline & & 0.2 & & 3 & 4 & 5 & & 6 \\
\hline & & $\begin{array}{r}10.1(0.7) \\
263.0(2.3)\end{array}$ & $\begin{array}{r}14.4 \\
277.4\end{array}$ & $\begin{array}{l}(0.7) \\
(1.7)\end{array}$ & $\begin{array}{r}21.0(0.6) \\
283.0(1.7)\end{array}$ & $\begin{array}{r}24.0 \\
288.0\end{array}$ & $\begin{array}{l}(1.1) \\
(1.9)\end{array}$ & $\begin{array}{r}30.5(0.9) \\
295.1(1.6)\end{array}$ \\
\hline Male & 3875 & $\begin{array}{r}10.1(0.9) \\
268.3(3.1)\end{array}$ & $\begin{array}{r}14.5 \\
283.6\end{array}$ & $\begin{array}{l}(0.9) \\
(1.8)\end{array}$ & $\begin{array}{r}19.5(0.7) \\
288.1(2.1)\end{array}$ & $\begin{array}{r}23.6 \\
293.0\end{array}$ & $\begin{array}{l}(1.1) \\
(2.4)\end{array}$ & $\begin{aligned} 32.2 & (1.2) \\
301.5 & (1.9)\end{aligned}$ \\
\hline Female & 3889 & $\begin{array}{r}10.0(0.9) \\
257.4(2.4)\end{array}$ & $\begin{array}{r}14.3 \\
270.9\end{array}$ & $\begin{array}{l}(0.8) \\
(2.2)\end{array}$ & $\begin{array}{r}22.5(0.8) \\
278.4(2.1)\end{array}$ & $\begin{array}{r}24.4 \\
283.0\end{array}$ & $\begin{array}{l}(1.2) \\
(1.8)\end{array}$ & $\begin{array}{r}28.8(1.1) \\
287.6(1.7)\end{array}$ \\
\hline white & 5507 & $\begin{array}{r}9.0(0.8) \\
270.1(2.9)\end{array}$ & $\begin{array}{r}13.9 \\
283.0\end{array}$ & $\begin{array}{l}(0.9) \\
(2.0)\end{array}$ & $\begin{aligned} 20.2 & (0.6) \\
289.1 & (1.8)\end{aligned}$ & $\begin{array}{r}24.5 \\
293.0\end{array}$ & $\begin{array}{l}(1.4) \\
(2.3)\end{array}$ & $\begin{aligned} 32.3 & (1.0) \\
299.5 & (1.7)\end{aligned}$ \\
\hline Black & 1273 & $\begin{array}{r}13.0(1.0) \\
248.6(3.2)\end{array}$ & $\begin{array}{r}16.0 \\
258.3\end{array}$ & $\begin{array}{l}(1.2) \\
(2.2)\end{array}$ & $\begin{array}{r}23.6(1.8) \\
259.6(1.9)\end{array}$ & $\begin{array}{r}23.5 \\
268.4\end{array}$ & $\begin{array}{l}(1.1) \\
(2.6)\end{array}$ & $\begin{array}{r}24.0(2.0) \\
272.2(2.5)\end{array}$ \\
\hline Hispanic & 755 & $\begin{array}{r}16.1(1.5) \\
247.4(3.7) \\
\end{array}$ & $\begin{array}{r}17.1 \\
262.1 \\
\end{array}$ & $\begin{array}{l}(2.4) \\
(5.0)\end{array}$ & $\begin{array}{r}23.8(1.8) \\
259.8(2.9) \\
\end{array}$ & $\begin{array}{r}20.8 \\
268.1 \\
\end{array}$ & $\begin{array}{l}(1.6) \\
(2.1) \\
\end{array}$ & $\begin{array}{r}22.1(2.2) \\
270.1(3.9) \\
\end{array}$ \\
\hline
\end{tabular}

Note. For each category of examinees, the first line shows the estimated percent of eleventh graders in the nation corresponding to each level of periods studied. The second line shows the history means on a scale with a mean of 285 and a standard deviation of 40 . Standard errors of percents and means are given in parentheses. 
The results of Analysis 2 are given in the lower margins of Tables $4-9$. In Tables 4, 5, and 6, which display the A, B, and C classifications, the results of Analysis 2 were nearly identical to those of Analysis 1. That few items changed classifications can be observed by noting that most of the offdiagonal elements are zeroes. Only in the White-Hispanic analyses were there some larger shifts and these were in the opposite directior to the predicted change: The number of items that were conditionally easier for Whites increased and the number of items that were conditionally easier for Hispanics decreased. Tables 7,8 , and 9 show results that are even more surprising: If only the statistical significance of the chi-square values was considered in classifying items, all three group comparisons yielded an increase in the number of items that showed DIF in favor of the reference group (see the cell in the first row and second column) and a decrease in the items that showed DIF in favor of the focal group (see the cell in the fourth row and third column). The most dranatic change was in the white-Hispanic analysis, in which 21 items that were conditionally easier for thites, but were not statistically significant in Analysis 1 became statistically significant in Analysis 2. Two basic questions were raised by these results:

1. Why did the classification of items as A, B, or C remain relatively constant, while the classification by statistical significance showed a substantial change between Analysis 1 and Analysis 2?

2. Why did the more refined matching produce at least as many items favoring the reference group as the original analysis, regardless of which classification method was used?

Substantive and technical aspects of these questions are addressed in the next two sections. 


\section{Substantive Issues}

What substantive phenomena might explain the unexpected finding that additional conditioning variables did not lead to a reduction in the number of DIF items? One possibility is that Periods Studied did not add any useful classification information, given score. If the probability of answering the history items correctly were independent of Periods Studied, given score, then Analysis 2 would be expected to produce the same results as Analysis 1 , as was indeed the case in terms of the $A, B$, and $C$ classifications. However, examination of the joint distribution showed that Periods Studied was not redundant with score. The Pearson correlations between the two variables were approximately .20 in each of the four history blocks.

Could any non-technical explanation account for an increase in the number of DIF items? One possibility is that "studying a topic" meant different things for different demographic groups. For instance, if the instruction to which minority students have access is inferior, in general. to that to which Whites have access, perhaps coverage of a topic is more likely to be inadequate for minorities. If this hypothesis were true, "mat ihing" on Periods Studied could have produced strata that were less homogereous than the strata of Analysis 1. This hypothesis would not seen to apply to male-female comparisons, however. A related hypothesis is that the demographic groups differed in their interpretation of the question about periods studied. It is possible that students who, in fact, had the same course background nevertheless responded differently to the question about periods studied and that these response tendencies were related to gender or ethnicity. If this were true, it would again be the case that the "matching" of Analysis 2 would not have resulted in greatre within-stratum homogeneity. 


\section{Technical Issues}

It might be hypothesized that the classification of items as $A, B$, and $C$ obscured a difference in results between Analyses 1 and 2 . To explore this hypothesis, three DIF statistics were examined in detail: MH D-DIF, MH D-DIF divided by its standard error (see Philips \& Holland, 1987) and MH CHISQ. For each of these three statistics, the 141 values from Analysis 2 were regressed on those from Analysis 1, yielding the following results:

$\begin{array}{lccc}\text { Statistic } & \text { Slope } & \text { Intercept } & \text { Correlation } \\ \text { MH D-DIF } & 1.0 & 0.0 & .98 \\ \text { MH D-DIF / SE } & 1.0 & 0.0 & .99 \\ \text { MH CHISQ } & 0.8 & 1.2 & .92\end{array}$

Clearly, only the MH CHISQ values differed across the two analyses. This is somewhat disconcerting, since the chi-square test has a more rigorous theoretical basis than the Mantel-Haenszel odds ratio estimator in Equation 6. One possible reason for the chi-square findings is that the complex sampling scheme has a differential effect on the two analysis methods. A more likely explanation is that the sparser tables of Analysis 2 cause the chi-square approximation to deteriorate. Each of these fossibilicies is discussed below.

Possible Differential Effect of Complex Sampling on Analyses 1 and 2

The effect of 'NAEP's complex sampling scheme on the distribution of MH CHISQ will depend upon the relation between the variables used for conditioning in the Mantel-Haerszel test and the variables uscd for defining clusters and strata in the sampling plan. Therefore, there is some possibility that the inpact of complex sampling on the distribution of MI 
CHISQ could differ for Analyses 1 and 2. Further study of the distribution of $M H D-D I F$ and MH CHISQ under complex sampling is under way.

\section{Possible deterioration of Chi-Square Approximation in Analysis 2}

At present, the most likely explanation for the discrepancy between the two analysis methods in the number of significant items is that the distribution of MH CHISQ is affected by the pattern of sparseness that occurs in the $2 \times 2$ tables of Analysis 2. The fact that the discrepancy is largest for the White-Hispanic analysis, which has the smallest sample size, seems to support this explanation. A simulation was conducted to determine whether the chi-square findings reflected meaningful information about the Periods Studied variable or whether they were artifactual. Using the actual data from the male-female analysis, the males at each score level were randomly allocated to an arbitrary stratification variable in such a way as to duplicate the joint distribution of score and Periods Studied; this process was repeated for females. A Mantel-Haenszel analysis was then conducted, producing results that were nearly identical to those of Analysis 2 . The table showing the association between the Analysis 1 and simulation results closely resembled Table 7 . Five replications of the simulation were performed, yielding essentially the same results. Further investigations of this phenomenon are in progress.

\section{Should Conditioning Variables In Addition to Score Be Used?}

It seems that in many af, lications, it would be desirable to judge as problematic only those items which show DIF for groups that have been equated on measures of course background, as well as ability. However, several drawbacks should be considered: 
1. Additional conditioning measures may not be readily available.

2. Adding conditioning variables may not increase within-stratum homogeneity, either because the available measures are so highly correlated with score that they do not contribute additional information, or because they are subject to errors of the kind described in this paper.

3. The sparser tables that result from multivariate matching may affect the properties of the Mantel-Haenszel chi-square.

In any case, the results of this study indicate that conditioning on additional variables within the Mantel-Haenszel franework does not necessarily decrease the number of items identified as having DIF. 


\section{References}

Applebee, A. N., Langer, J. A., \&Mullis, I. V. S. (1987). Literature \& U.S. history: The instructional experience and factual knowledge of. high school juniors. (NAEP Report No. 17-HL-01). Princeton, NJ: Educational Testing Service.

Hoiland, P. W., \& Thayer, D. T. (1988). Differential item performance and the Mantel-Haenszel procedure. In $H$. Wainer and $H$. I. Braun (Eds.), Test Validity, pp. 129-145. Hillsdale, NJ: Erlbaum.

Mantel, N. \& Haenszel, W. (1959). Statistical aspects of the analysis of data from retrospective studies of disease. Journal of the National Cancer Institute, 22, $719-748$.

Phillips, A., \& Holland, P. W. (1987). Estimators of the variance of the Mantel-Haenszel log-odds-ratio estimate. Biometrics, 43, 425-431.

$3:$ 